\title{
Evidence-based guideline: The role of diffusion and perfusion MRI for the diagnosis of acute ischemic stroke
}

\section{Report of the Therapeutics and Technology Assessment Subcommittee of the American Academy of Neurology}

(6)

P.D. Schellinger, MD, $\mathrm{PhD}$

R.N. Bryan, MD, PhD

L.R. Caplan, MD

J.A. Detre, MD

R.R. Edelman, MD

C. Jaigobin, MD

C.S. Kidwell, MD

J.P. Mohr, MD

M. Sloan, MD, MS

A.G. Sorensen, MD

S. Warach, MD, PhD

Address correspondence and reprint requests to the American Academy of Neurology, 1080 Montreal Avenue, St. Paul, MN 55116

guidelines@aan.com

Supplemental data at www.neurology.org

\section{ABSTRACT}

Objective: To assess the evidence for the use of diffusion-weighted imaging (DWI) and perfusionweighted imaging (PWI) in the diagnosis of patients with acute ischemic stroke.

Methods: We systematically analyzed the literature from 1966 to January 2008 to address the diagnostic and prognostic value of DWI and PWI.

Results and Recommendations: DWI is established as useful and should be considered more useful than noncontrast CT for the diagnosis of acute ischemic stroke within 12 hours of symptom onset. DWI should be performed for the most accurate diagnosis of acute ischemic stroke (Level A); however, the sensitivity of DWI for the diagnosis of ischemic stroke in a general sample of patients with possible acute stroke is not perfect. The diagnostic accuracy of DWI in evaluating cerebral hemorrhage is outside the scope of this guideline. On the basis of Class II and III evidence, baseline DWI volumes probably predict baseline stroke severity in anterior territory stroke (Level B) but possibly do not in vertebrobasilar artery territory stroke (Level C). Baseline DWI lesion volumes probably predict (final) infarct volumes (Level B) and possibly predict early and late clinical outcome measures (Level C). Baseline PWI volumes predict to a lesser degree the baseline stroke severity compared with DWI (Level C). There is insufficient evidence to support or refute the value of PWI in diagnosing acute ischemic stroke (LevelU). Neurology ${ }^{\circledR}$ 2010;75:177-185

\section{GLOSSARY}

ADC = apparent diffusion coefficient; ASPECTS = Alberta Stroke Program Early CT Score; $\mathbf{C B F}=$ cerebral blood flow; $\mathbf{C l}=$ confidence interval; DWI = diffusion-weighted imaging; $\mathbf{I C H}=$ intracerebral hemorrhage; $\mathbf{M R}$ = magnetic resonance; NIHSS = National Institute of Health Stroke Scale; PWI = perfusion-weighted imaging; $\mathbf{P A}=$ tissue plasminogen activator.

Stroke is the third leading cause of death and the leading cause of permanent disability and disabilityadjusted loss of independent life-years in Western countries. Presently, the only specific, approved therapy for acute ischemic stroke is IV tissue plasminogen activator (tPA) given within 4.5 hours. ${ }^{2-6}$ tPA use has been limited due to the short treatment window, concerns about the limitations of CT-based diagnosis, and fear of hemorrhagic risks.

Noncontrast CT is the current diagnostic standard for acute stroke due to its wide availability and presumed near-perfect sensitivity for acute intracerebral hemorrhage (ICH), ${ }^{7,8}$ the most impor- tant differential diagnosis to ischemic stroke. For ischemic infarction, a number of early signs have been described ${ }^{9}$ and formalized CT scores have been developed. ${ }^{10}$ The sensitivity of CT in acute ischemic stroke varies, depending on the imaging features of infarction, examination time from clinical onset, study population, and other variables. Sensitivity estimates range from $12 \%$ to $92 \%$, with an overall estimate of $40 \%-60 \%$ for the 6-hour time window. ${ }^{11} \mathrm{~A}$ post hoc analysis of the CT data from the National Institute of Neurological Disorders and Stroke tPA study yielded a 31\% sensitivity for early infarct signs. ${ }^{12}$ Despite the fact

\footnotetext{
From the National Institutes of Neurological Disorders and Stroke (P.D.S., S.W.), NIH, Bethesda, MD; Department of Neurology (P.D.S.), University of Erlangen, Germany; Departments of Radiology (R.N.B.) and Neurology (J.A.D.), University of Pennsylvania, Philadelphia; Department of Neurology (L.R.C.), Beth Israel Deaconess Medical Center, Boston, MA; Department of Radiology (R.R.E.), Northwestern University, Evanston, IL; Division of Neurology (C.J.), Toronto General Hospital, Canada; Department of Neurology (C.S.K.), Georgetown University, Washington, DC; Columbia University (J.P.M.), New York, NY; Department of Neurology (M.S.), University of South Florida, Tampa; and Department of Radiology (A.G.S.), MGH, Boston, MA.

Appendices e-1-e-6 and references e1-e7 are available on the Neurology ${ }^{\circledR}$ Web site at www.neurology.org.

Approved by the Therapeutics and Technology Assessment Subcommittee on November 15, 2008; by the Practice Committee on August 4, 2009; and by the AAN Board of Directors on April 25, 2010.

Disclosure: Author disclosures are provided at the end of the article.
} 
that CT accuracy in acute stroke has never been established by formal assessment of the evidence relative to an independent standard, CT has become the de facto diagnostic standard.

As noncontrast CT has limited sensitivity for the diagnosis of ischemic stroke in the initial hours, improved accuracy of stroke diagnosis is necessary for the development and application of optimal thrombolytic and other stroke therapy. ${ }^{12,13}$ New MRI techniques such as diffusion-weighted imaging (DWI) and perfusion-weighted imaging (PWI) add another dimension to diagnostic imaging ${ }^{14,15}$ and have the potential to improve the diagnostic yield while being practical and feasible.

DWI measures the net movement of water in tissue due to random (Brownian) molecular motion of water and shows hyperintense ischemic tissue changes within minutes to a few hours after arterial occlusion due to a reduction of the apparent diffusion coefficient (ADC). ${ }^{16,17}$ The ADC reduction occurs primarily in the intracellular space associated with disruption in membrane ionic homeostasis and cytotoxic edema. Decreases in the ADC and increased signal on DWI studies in many instances represent irreversible ischemia. To differentiate acute from subacute or older lesions (T2 shine-through), DWI is used in conjunction with T2-weighted images and ADC maps.

PWI allows the measurement of capillary perfusion. The method most commonly used in clinical practice and research is the dynamic susceptibility contrast-enhanced technique, in which paramagnetic contrast agent is injected as an IV bolus and the signal change is tracked by susceptibility-weighted, T2*-weighted magnetic resonance (MR) sequences. ${ }^{18}$ Relative cerebrovascular hemodynamic measures reflecting cerebral blood volume, mean transit time, time to peak, and cerebral blood flow (CBF) can be derived from the MR signal intensity-over-time curve in a semiquantitative fashion. Parameter maps display the area of critically reduced perfusion.

Although studies have overcome the usual logistical obstacles to the emergency use of MRI, 19,20 doubts remain regarding the feasibility, practicality, and validity of stroke MRI in the clinical setting. As there is no true imaging gold standard for acute ischemic stroke that has been established by comparison with neuropathologic findings, ${ }^{21}$ the reference diagnosis of ischemic stroke in most MRI studies is established using a follow-up lesion on CT or conventional MR images consistent with the clinical syndrome and a comprehensive diagnostic workup.
We sought to answer the following questions regarding the accuracy, sensitivity, and specificity of MRI use in acute ischemic stroke:

1. Are DWI and PWI sensitive and specific in the diagnosis of acute ischemic stroke (compared to concurrent imaging with other techniques, established by follow-up imaging, clinical follow-up, and final discharge diagnosis)?

2. Does the volume of the DWI or PWI abnormality predict initial clinical severity, final infarct size, and late clinical outcome?

We addressed these questions solely from the standpoint of diagnostic accuracy. In clinical practice, whether MRI or CT should be performed depends on additional factors that are outside the scope of this assessment. For the second question, the term predict was used instead of correlate. Correlate is a generic term for a measure of association or a specific technique for a measure of the strength of association between continuous variables. Because we reviewed evidence on the basis of both the correlation between continuous variables and the association with dichotomous outcomes, the more generic term "predict" sused in formulating this question.

DESCRIPTION OF THE ANALYTIC PROCESS A panel of neurologists, neuroradiologists, and radiologists was assembled. The panel performed a literature search through January 2008 in the following databases: Medline (starting 1966), Embase (starting 1974), Biosis (starting 1969), and Sci (starting 1990). The exact keyword search is available in appendix e-1 on the Neurology ${ }^{\circledR}$ Web site at www.neurology.org.

We identified 492 abstracts for question 1 (DWI), 213 for question 1 (PWI), and 210 for question 2. Two panel members reviewed each abstract. Exclusion criteria were as follows: 1) unrelated to acute ischemic stroke $<12$ hours (question 1) or $<24$ hours (question 2) after symptom onset or unrelated to questions; 2) unrelated to DWI or PWI (i.e., CT, T2-weighted imaging, Xe-CT, PET, SPECT); 3) case report or case series with $\mathrm{n}<15$; 4) review article; 5) letter to the editor or editorial; 6) involving pediatric patients or nonhuman subjects; or 7) nonclinical (e.g., technique development). The eligible publications of each pair were discussed with the whole panel to produce a final list of articles for each question.

We chose a time window of 12 hours for question 1 because most treatment studies for acute stroke have an inclusion window of $<12$ hours. DWI and PWI have a high diagnostic accuracy within the first hours, and effective treatment of acute stroke is negatively correlated with time from symptom onset. 
Studies that included patients in a time window exceeding 12 hours were considered for inclusion if a subset of patients $<12$ hours was reported or the numbers for such a subset could be extracted. For question 2, we chose a time window of 24 hours and a sample size of 30 or more for inclusion. Furthermore, we excluded studies in which any patients received thrombolytic therapy so as not to confound the prognostic value of DWI and PWI with regard to the natural disease course.

Recently reported large open series, ${ }^{22,23}$ phase II and III randomized, placebo-controlled trials of MRI-guided IV thrombolysis in acute stroke (DIAS, DEDAS, DIAS-2, EPITHET) ${ }^{24-27}$ are a case in point. These trials selected patients for inclusion up to 9 hours from stroke onset on the basis of a qualitative MRI penumbral pattern. For this assessment, only the placebo groups of these trials would be eligible and helpful in judging diagnostic accuracy (question 1) or predictive value for baseline clinical status and clinical or structural outcome (question 2). No separate imaging data are available for any of these studies yet; in EPITHET, only summary data and the subgroups with PWI/DWI mismatch are presented.

Evidence was classified using a 4-tier classification scheme for diagnostic (question 1) and prognostic (question 2) articles (appendices e-2 and e-3), and recommendations were based on these levels of evidence (appendix e-4). If more than one publication from identical groups entered data extraction, the manuscripts were assessed for the same patients being used in different analyses. In this case, the publication with the highest class of evidence and patient number was included. After the selection process, panel members discussed potentially relevant publications that could change the level of recommendation. These studies were included or excluded by consensus.

ANALYSIS OF EVIDENCE Question 1: Are DWI and PWI sensitive and specific in the diagnosis of acute ischemic stroke (compared to concurrent imaging with other techniques, established by follow-up imaging, clinical follow-up, and final discharge diagnosis)? We identified 62 studies fulfilling the inclusion criteria. Twenty-six were excluded due to patient overlap with other studies of the same investigator groups. Of the remaining 36 articles, 32 are not discussed further because they consisted of Class III $(\mathrm{n}=4)$ and IV $(\mathrm{n}=28)$ evidence.

For DWI, there was 1 Class $\mathrm{I}^{28}$ and 3 Class II studies $^{7,13,29}$; all PWI studies were Class IV. The Class I study assessed the accuracy of MRI (DWI and gradient echo scans) vs CT in 356 consecutive patients presenting to a hospital emergency department over an 18-month period in whom the emergency physician diagnosed possible acute stroke. ${ }^{28}$ There- fore, ischemic strokes, nonischemic strokes, and stroke mimics were included. Patients with the suspected diagnosis of acute stroke were imaged a median of 34 minutes earlier by MRI than CT. Two neuroradiologists and 2 stroke neurologists independently interpreted all scans, blinded to clinical information and CT-DWI pairings. In the subset of 221 patients scanned within 12 hours of onset, the majority of readers correctly diagnosed acute ischemic stroke by MRI more often than by CT (94 vs 22, $p<$ $0.0001)$. The odds ratio and its $95 \%$ confidence interval $(\mathrm{CI})$ of the difference in the proportions was 25 (8-79), indicating an effect size sufficiently large for this single study to justify a Level A recommendation. A similar direction and magnitude of difference were also seen in the subset of 90 patients scanned within 3 hours of onset. Relative to the final hospital discharge diagnosis (based on follow-up imaging and clinical syndrome), the sensitivity, specificity, and accuracy of DWI were $77 \%, 96 \%$, and $86 \%$, and of CT were 16\%, 97\%, and 55\%. These sensitivities are lower than in other series, which may indicate vulnerability to selection bias, as they lacked a cohort of nonstroke controls and underrepresented milder strokes that were seen in this sample (median $\mathrm{Na}$ onal Institute of Health Stroke Scale [NIHSS] score was 4). The performance of baseline imaging in predicting final diagnosis is limited by the fact that all imaging findings were available in the hospital medical record to clinicians who made the discharge diagnosis.

A Class II study prospectively evaluated 50 patients with ischemic stroke and 4 patients with TIAs. ${ }^{13}$ Patients were randomized to receive MRI or CT within 6 hours of stroke onset. The independent diagnosis of stroke was established by the clinical course and follow-up CT or MRI. Five stroke experts and 4 residents independently judged the images. They were blinded to the patients' symptoms and signs but were aware that the cohort was an ischemic stroke population. The sensitivity of infarct detection by the experts was significantly better when based on DWI (91\%) than CT (61\%), as was the accuracy: DWI (91\%), CT (61\%). Interrater variability of lesion detection was also significantly better for DWI $(\kappa=0.84)$ than for CT $(\kappa=0.51)$. DWI had good interrater homogeneity and better sensitivity and accuracy than CT, even if the raters had limited experience.

The discrimination of ischemic from hemorrhagic stroke was studied in a Class II prospective multicenter study of 62 patients with ICH or ischemic stroke who were assessed within 6 hours (mean 3 hours 23 minutes) with DWI, T2-weighted imaging, and T2*-weighted imaging. ${ }^{7}$ Baseline CT, 
follow-up imaging, and clinical course were used to establish the diagnosis of ischemic stroke and $\mathrm{ICH}$. Three blinded raters independently rated all scans. All ischemic strokes and ICHs were correctly identified. Because the aim of this study was to evaluate whether MRI with DWI could differentiate ischemic stroke from ICH within the first 6 hours, the spectrum of patients and controls was narrow. This study is pertinent to the diagnostic strength of CT and MRI for both ischemic and hemorrhagic stroke; however, the latter is outside the parameters of this report and is not addressed further.

A final Class II prospective study of 100 patients compared DWI and CT with a blinded image analysis. ${ }^{29}$ CT was performed first within 6 hours of symptom onset, followed by DWI within 7 hours of symptom onset. Because 39 patients received tPA, the study was excluded for question 2. Five blinded readers applied the Alberta Stroke Program Early CT Score (ASPECTS $)^{10}$ for both CT and DWI and validated the scores by follow-up imaging. The ASPECTS is a formalized CT-derived score used to evaluate the degree of ischemic changes in the middle cerebral artery territory. DWI and CT ASPECTS were positively related $(\alpha<$ 0.001). Of CT scans with ASPECTS of $8-10,81 \%$ had DWI ASPECTS of 8-10. Early CT changes were found in 66\% of patients (CI 56-75), and DWI abnormalities were found in $81 \%$ of patients (CK 72-88; nonsignificant). However, the median CT ASPECTS was 9 and the median DWIASPECTS was 8, indicating that lesions are more conspicuous with the latter method.

Table 1 summarizes the results of the 4 Class I and II studies that address question 1.

Conclusions. DWI is established as superior to CT for the diagnosis of acute ischemic stroke within 12 hours of symptom onset (1 Class I study with large effect). The diagnostic accuracy of DWI in the evaluation of hemorrhagic stroke is outside the scope of this review. There was no evidence rated better than Class IV to determine the diagnostic accuracy of PWI.

Question 2: Does the volume of the DWI or PWI abnormality predict initial clinical severity, final infarct size, and late clinical outcome? We identified 8 studies fulfilling the inclusion criteria. Of these, 4 Class IV studies assessed only the correlation of baseline DWI and PWI lesion volume with chronic lesion volume, ${ }^{30-33} 1$ Class II study assessed only the correlation of baseline DWI and PWI lesion volume with clinical outcome, ${ }^{34}$ and 2 Class II studies and 1 Class III study assessed both clinical and morphologic outcome. ${ }^{35-37}$ None of the identified studies compared CT with MRI in predicting these outcomes.

One Class II study investigated whether DWI is useful for clinicoradiologic correlation of posteriorcirculation ischemia within 24 hours of symptom onset and whether NIHSS score correlates with lesion volumes in patients with posterior-circulation stroke. ${ }^{34}$ Using imaging and clinical criteria, 115 of 631 patients $(18 \%)$ had symptoms of posteriorcirculation ischemia. Of these 115,40 patients fulfilled the inclusion criteria with regard to time window and available imaging data. An acute lesion corresponding to the patient's symptoms was detected in all 40 patients on DWI but in only 16 patients on T2-weighted imaging. Acute lesion volume did not correlate with NIHSS score $(\mathrm{n}=40$; rho $=$ $0.3 ; p=0.06$ ). The authors conclude that DWI has a higher diagnostic accuracy than T2-weighted imaging in patients with acute posterior-circulation

Table 1

Class I and II studies for question 1: Is DWI sensitive and specific in the diagnosis of acute ischemic stroke?

\begin{tabular}{|c|c|c|c|}
\hline Author (year) & Objectives, design & Results & $\begin{array}{l}\text { Class of } \\
\text { evidence }\end{array}$ \\
\hline $\begin{array}{l}\text { Chalela et al. }{ }^{28} \\
\text { (2007) }\end{array}$ & $\begin{array}{l}\text { Diagnostic accuracy of DWI (and GRE) compared } \\
\text { to CT and final clinical diagnosis for acute stroke } \\
\text { (ischemic and hemorrhagic). Total sample = 356; } \\
221<12 \text { hours. Majority opinion of blinded, } \\
\text { independent reads by panel of } 4 \text { experts. } \\
\text { Representative and broad spectrum of patients } \\
\text { with clinical suspicion of stroke by emergency } \\
\text { physician (actual diagnosis: ischemic stroke, TIA, } \\
\text { primary hemorrhage, not cerebrovascular). MRI } \\
\text { obtained earlier than CT by } 34 \text { minutes. }\end{array}$ & $\begin{array}{l}\text { MRI superior to CT for acute ischemic stroke } \\
\text { detection < } 12 \text { hours from onset: OR ( } 95 \% \\
\text { CI) = } 25 \text { (8-79). CT: sensitivity 16\%, } \\
\text { specificity } 97 \% \text {, accuracy } 55 \% \text {; MRI: } \\
\text { sensitivity } 78 \% \text {, specificity } 96 \% \text {, accuracy } \\
86 \%\end{array}$ & I \\
\hline $\begin{array}{l}\text { Fiebach et al. }{ }^{13} \\
(2002)\end{array}$ & $\begin{array}{l}\text { Randomized comparison of CT and DWI in } \\
\text { ischemic stroke }<6 \text { hours. CT before DWI by } 9 \\
\text { minutes. }\end{array}$ & $\begin{array}{l}\text { Sensitivity experts: CT 61\% (range 52\%- } \\
\text { 70\%); DWI 91\% (range 88\%-94\%); } \\
\text { sensitivity novices: CT 46\% (range 32\%- } \\
64 \% \text { ); DWI } 81 \% \text { (range } 78 \%-86 \% \text { ) }\end{array}$ & II \\
\hline $\begin{array}{l}\text { Fiebach et al. } \\
(2004)\end{array}$ & $\begin{array}{l}\text { Diagnostic accuracy of } \mathrm{T} 2, \mathrm{~T}^{*} \text {, DWI to } \\
\text { discriminate ischemic stroke from ICH. }\end{array}$ & $\begin{array}{l}\text { Sensitivity: } 100 \% \text { (95\% Cl 97.1\%-100\%); } \\
\text { specificity, PPV, NPV, accuracy: 100\% }\end{array}$ & ॥ \\
\hline $\begin{array}{l}\text { Barber et al.29 } \\
(2005)\end{array}$ & $\begin{array}{l}\text { Diagnostic accuracy of CT and DWI }<6 \text { (7) hours } \\
\text { by ASPECTS score. CT always before DWI. }\end{array}$ & $\begin{array}{l}\text { Sensitivity: CT: 66\% (66/100, Cl 56-75); } \\
\text { DWI: } 81 \%(81 / 100, \mathrm{Cl} 72-88)\end{array}$ & II \\
\hline
\end{tabular}

Abbreviations: ASPECTS = Alberta Stroke Program Early CT Score; $\mathrm{Cl}=$ confidence interval; DWI = diffusion-weighted imaging; GRE = gradient echo; NPV = negative predictive value; $\mathrm{OR}=$ odds ratio; $\mathrm{PPV}=$ positive predictive value. 
strokes and suggest that DWI lesion volumes do not correlate with NIHSS score because the NIHSS score may be less valid in posterior-circulation than in anterior-circulation stroke symptoms.

Another Class II study ${ }^{36}$ assessed 50 patients diagnosed with acute ischemic middle cerebral artery territory stroke (<24-hour duration) with DWI. Thirty-four patients had volumes measured by T2weighted imaging chronically (median 7.5 weeks). Acute lesion volumes correlated with the acute $(r=$ $0.56-0.61, p<0.0001)$ and chronic $(r=0.63, p<$ $0.0001)$ NIHSS and with chronic lesion volumes $(r=0.84-0.90, p<0.0001)$. The correlation of acute DWI lesion volume with the chronic Barthel Index was moderate $(r=-0.33, p=0.034)$.

A final Class II study examined DWI and PWI characteristics in a neuroprotective double-blind placebo-controlled study involving patients with acute ischemic stroke. ${ }^{37}$ Patients with acute ischemic stroke symptom onset 24 hours or less before the start of treatment, NIHSS scores of 5 or higher, and lesions of 1 to $120 \mathrm{~mL}$ in cerebral gray matter by DWI were enrolled. Of the 100 patients enrolled, 81 had interpretable MR measurements. Baseline DWI and PWI lesion volumes correlated with baseline NIHSS scores $(r=0.64$ and $r=0.49$, both $p<$ 0.001). Baseline DWI volume also correlated with follow-up lesion volume at 12 weeks $(r=0.79, p<$ $0.001)$. The authors conclude that significant correlations between lesion volumes and clinical measures were found, replicating values reported in the literature for smaller case series, and suggest that this relationship supports the role of DWI as a clinically meaningful surrogate markerin stroke clinical trials.

The aim of the Class III study ${ }^{35}$ was to investigate whether the relationship between acute NIHSS score and acute stroke volume (as determined by acute DWI and PWI) differs between right-sided and leftsided stroke. This difference may be important if a low NIHSS score is used to exclude patients with right-hemisphere stroke from clinical trials or established treatments. A total of 153 patients were retrospectively assessed with MRI within 24 hours of stroke onset. There were correlations between the acute NIHSS scores and acute DWI lesion volumes $(r=0.48$ right, $r=0.58$ left, $p<0.0001)$ and between acute NIHSS scores and PWI hypoperfusion volumes $(r=0.62$ right, $r=0.60 \mathrm{left}, p<$ $0.0001)$. However, multiple linear regression analysis revealed a lower acute NIHSS score on the right side compared to the left when adjusted for stroke volume on follow-up T2 imaging ( $p=0.03)$. The authors concluded that patients with right hemispheric stroke may have a lower NIHSS despite substantial acute stroke volume defined by DWI and PWI, and these imaging modalities may be more useful than the NIHSS in identifying patients who may be eligible for acute stroke protocols.

A combination of the baseline NIHSS score, time rom stroke onset to DWI, and the baseline lesion volume on DWI was an independent predictor of clinical outcome (3-month Barthel Index) in a logistic regression model. ${ }^{38}$ The model was externally validated with a $77 \%$ sensitivity and $88 \%$ specificity. A similar retrospective study of 63 patients investigated whether the baseline DWI lesion volume was an independent predictor of functional outcome. ${ }^{39}$ In both instances, the derivation and validation groups were very small.

Table 2 summarizes the results of the 3 Class II studies that address question 2.

Conclusions. Baseline DWI volume probably predicts baseline clinical stroke severity and final lesion

Table 2 Class II studies for question 2: Does the volume of the DWI or PWI abnormality correlate with initial clinical severity, final infarct size, and late clinical outcome?

\begin{tabular}{|c|c|c|c|}
\hline Author (year) & Objectives, design & Results & $\begin{array}{l}\text { Class of } \\
\text { evidence }\end{array}$ \\
\hline $\begin{array}{l}\text { Linfante et al. }{ }^{34} \\
\text { (2001) }\end{array}$ & $\begin{array}{l}\text { Prognosis of DWI lesion volume and clinical } \\
\text { outcome measured with NIHSS in patients } \\
\text { with posterior circulation ischemia within } \\
24 \text { hours of symptom onset. }\end{array}$ & $\begin{array}{l}\text { DWI lesion volume did not correlate with NIHSS } \\
(\text { rho }=0.3 ; p=0.06)\end{array}$ & II \\
\hline $\begin{array}{l}\text { Lovblad et al. }{ }^{36} \\
\text { (1997) }\end{array}$ & $\begin{array}{l}\text { Prognosis of DWI lesion volume and } 1 \text { ) } \\
\text { clinical measures during acute and chronic } \\
\text { stages after MCA territory stroke; 2) } \\
\text { chronic lesion volume. }\end{array}$ & $\begin{array}{l}\text { DWI lesion volumes correlated with the acute } \\
(r=0.56-0.61, p<0.0001) \text { and chronic }(r= \\
0.63, p<0.0001) \text { NIHSS with moderate } \\
\text { correlation with chronic Barthel Index ( } r= \\
-0.33, p=0.034) \text {. DWI lesion volume } \\
\text { correlated with chronic lesion volumes }(r= \\
0.84-0.90, p<0.0001)\end{array}$ & II \\
\hline $\begin{array}{l}\text { Warach et al. }{ }^{37} \\
(2000)\end{array}$ & $\begin{array}{l}\text { Correlation of DWI and PWI lesion volume } \\
\text { within } 24 \text { hours of symptom onset with } \\
\text { acute stroke severity measured with } \\
\text { NIHSS. Prognosis of baseline DWI volume } \\
\text { and chronic lesion volume. }\end{array}$ & $\begin{array}{l}\text { Baseline DWI and PWI lesion volumes } \\
\text { significantly correlated with baseline NIHSS } \\
\text { scores }(r=0.64 \text { and } r=0.49 \text {, both } p<0.001) \text {. } \\
\text { Baseline DWI volume correlated with follow-up } \\
\text { lesion volume at } 12 \text { weeks }(r=0.79, p< \\
0.001)\end{array}$ & II \\
\hline
\end{tabular}

Abbreviations: $\mathrm{DWI}=$ diffusion-weighted imaging; $\mathrm{MCA}=$ middle cerebral artery; NIHSS = National Institute of Health Stroke Scale; $\mathrm{PWI}=$ perfusion-weighted imaging. 
volume in anterior-circulation stroke syndromes (multiple Class II studies) and is possibly accurate in predicting clinical outcome as measured by the NIHSS and Barthel Index (1 Class II study). Baseline DWI volume possibly does not predict the baseline NIHSS score in posterior-circulation stroke syndromes (1 Class II study). Baseline PWI volume possibly predicts baseline clinical stroke severity (1 Class II study).

\section{RECOMMENDATIONS}

1. DWI should be considered superior to noncontrast CT scan for the diagnosis of acute ischemic stroke in patients presenting within 12 hours of symptom onset (Level A).

2. There is insufficient evidence to support or refute the value of PWI in diagnosing acute ischemic stroke (Level U).

3. Baseline DWI volume should be considered useful in predicting baseline clinical stroke severity and final lesion volume in anterior-circulation stroke syndromes (Level B).

4. Baseline DWI volume may be considered not useful in predicting baseline NIHSS score in posterior-circulation stroke syndromes (Level C).

5. Baseline DWI volume may be considered useful in predicting clinical outcome as measured by the NIHSS and Barthel Index (Level C)

6. Baseline PWI volume may be considered useful in predicting baseline clinical stroke severity (Level C).

CLINICAL CONTEXT In patients presenting with acute neurologic impairment, noncontrast CT imaging is used to evaluate for infarct and to exclude hemorrhage and other structural lesions that may mimic stroke. The evidence from our report demonstrates that DWI is accurate and superior to CT for the diagnosis of acute ischemic stroke ${ }^{7,13,28,29}$ relative to clinical and imaging outcomes. However, in clinical practice, the availability and cost of imaging modalities and the requirements of medical management enter into the decision about which test to perform in the acute period.

The true sensitivity of DWI for the diagnosis of ischemic stroke is not $100 \%$ and is probably closer to $80 \%-90 \%$ in a general sample of patients presenting for emergency evaluation of possible stroke. Many of the initial case series and small CT comparative studies reported a near- $100 \%$ sensitivity for DWI in the hyperacute stage of stroke $\mathrm{f0}^{401, \mathrm{e} 2}$ in highly selected subsets of patients. Increasingly, however, cases of DWI-negative stroke were reported. ${ }^{\text {e3 }}$ False-negative DWI in ischemic stroke may be attributable to mild (small) strokes, brainstem location, and the earliest times from onset, and may become less frequent as imaging technology continues to improve.

DWI-positive scans in TIA are common. According to the literature, acute ischemic DWI lesions are present in $40.1 \%$ of patients with the clinical diagnosis of a TIA (10 studies, 234/584 patients), a finding that correlates with symptom duration. ${ }^{\text {e4,e5 }}$ Only one of the studies involved DWI performed within 24 hours of symptom onset. ${ }^{\text {e6 }}$ A recent study estimated the epidemiologic impact of DWI-based diagnosis would result in reduced annual TIA incidence (33\%) and increased stroke incidence $(7 \%)$ in the United States. $^{\text {e7 }}$

\section{RECOMMENDATIONS FOR FUTURE RESEARCH}

1. Prospective, well-designed studies on the diagnostic utility of PWI in acute stroke are needed.

2. Hypoperfusion remains a key pathophysiologic mechanism in stroke. However, it is not known if absolute quantification of $\mathrm{CBF}$ at any one moment in time is sufficient for diagnosis or prediction of tissue outcome. If the predictive value of such hemodynamic measures can be validated, semiquantitative or qualitative assessment rather than quantitative techniques (e.g., ${ }^{15} \mathrm{O}-\mathrm{PET}$ scanning) may suffice. There are also newer techniques of PWI on the horizon that provide more quantitative parameters. Which current and which future approaches have superior diagnostic and prognostic utility should be investigated, or a consensus to permit consistent and definitive studies on the use of PWI in acute stroke should be reached.

3. Integration of clinical and laboratory data with DWI in combination with MRA-derived and PWI-derived parameters toward the goal of improving diagnostic utility and prediction of patient outcome and tissue fate should be investigated.

4. The role of DWI-derived and PWI-derived measures as therapeutic selection criteria and as markers of treatment response requires continued study. These promising approaches toward expanding the treatment indications for acute stroke will need to be validated.

5. Further investigation is required to establish the predictive value of DWI-derived lesion volumes within the first hours from onset and the potential added value of PWI measures, as well as to address cost-benefit issues in appropriate medicoeconomic studies.

\section{DISCLOSURE}

Dr. Schellinger has served/serves on scientific advisory boards for Boehringer Ingelheim, ImaRx Therapeutics, Photothera, Cerevast, and CoAxia, Inc.; has served/serves on speakers' bureaus for and received funding for 
travel and speaker honoraria from Boehringer Ingelheim, Sanofi, ImaRx Therapeutics, Photothera, Cerevast, CoAxia, Inc., Solvay Pharmaceuticals, Inc., and GlaxoSmithKline; serves on editorial boards of Stroke and European Neurology; receives royalties from the publication of NeuroIntensiv (Springer, 2008) and received royalties from the publication of Stroke MRI (Steinkopff, 2004); has served as a consultant for CoAxia, Inc., Photothera, Cerevast, ImaRx, and Boehringer Ingelheim; and has provided expert testimony, affidavits, and acted as a witness or consultant in legal proceedings. Dr. Bryan serves as an Associate Editor of Radiology, on the editorial boards of Magnetic Resonance in Medicine and Contemporary Diagnostic Radiology, and on the editorial executive committee of Academic Radiology; has received research support from Wyeth and the NIH (NO1HC-95178 [Sub Contract PI] and N01-WH-4-4221 [Sub Contract PI]); and estimates that $40 \%$ of his clinical effort is spent performing CT and $40 \%$ is spent performing MRI. Dr. Caplan serves on scientific advisory boards for Boehringer Ingelheim, Genentech, Inc., LifeCycle Pharma A/S, ReNeuron, Novovision, Inc., NeuroLogica Corporation, and Avani Pharmaceuticals; serves as a consultant to Micromedex, AstraZeneca, Bayer Schering Pharma, Takeda Pharmaceutical Company Limited, CoAxia, Inc., Millennium Pharmaceuticals, Inc., Jones \& Davis L.L.P., and Novo Nordisk; has served on a speakers' bureau for Otsuka Pharmaceutical Co., Ltd.; serves as Co-editor of Reviews in Neurological Diseases and on the editorial board of Archives of Neurology; and receives royalties from the publication of Blueprints in Neurology, 2nd ed. (Lippincott Williams \& Wilkins, 2006), Brain Embolism (Informa Healthcare, 2006), Case Studies in Stroke: Common and Uncommon Presentations (Cambridge University Press, 2006), Intracranial Atherosclerosis (Wiley-Blackwell, 2008), Uncommon Causes of Stroke, 2nd ed. (Cambridge University Press, 2008), an Caplan's Stroke: A Clinical Approach, 4th ed. (Elsevier, 2009). Dr. De serves on a scientific advisory board of Pittsburgh NMR Center; serves as an Associate Editor of the Journal of Neuroimaging; serves as a consultan for Pfizer Inc; receives research support from Wyeth, AstraZeneca, Pfize Inc, the National Science Foundation and from the NIH (R01 MH080729 [PWI], K24 NS058386 [PWI],P30 NS045839 [PWI], T32 NS054575 [PWI], R01 NS060653 [Co-I], R04 NS061572 [Co-I], P41 RR002305 [PWI], R24 HD050836 [PWI], R24 HD050838 [Co-I], R01 NS057400 [Co-I], R01 DK085615 [Co-I], R01AG034682 [Co-1], R21 DA025882 [Co-I], R01 HL102119 [Co-I], R03 DA027098 [Co-I], R24 HD050836 [Co-I]); is an inventor on a patent re: ASC Perfusion MRI and receives royalties from the University of Pennsylvania for its licensure; and has acted as a witness or consultant in legal proceedings. Dr. Edelman serves as an Associate Editor for Investigative Radiology; has received research support from Siemens Healthcare; and holds a provisional patent re: non-contrast MR angiography and receives license fee payments from Siemens Healthcare, Dr. Jaigobin has received speaker honoraria from sanofi-aventis and Boehringer Ingelheim. Dr. Kidwell serves on the editorial boards of Neuracritical Care Journal, the Journal of Neuroimaging, and Stroke Research and Treatment; has served as a consultant for Embrella Cardiovascular, Inc.; and receives research support from Baxter International Inc., and the NIH (NINDS P50 NS044378 [Co-I] and NINDS U54 NS057405 [PWI]). Dr. Mohr serves on scientific advisory boards for Mitsubishi Tanabe Pharma Corporation and Schering-Plough Corp.; serves on the editorial board of Cerebrovascular Diseases and as Chief Editor of Stroke; receives royalties from the publication of Stroke: Pathophysiology, Diagnosis, and Management 4th ed. (Churchill Livingstone, 2004), serves as a consultant for Schering-Plough Corp.; and has given expert testimony on PFO and unruptured aneurysms. Dr. Sloan serves on the editorial boards of the Journal of Neuroimaging, Stroke, and the Journal of Stroke and Cerebrovascular Diseases; holds financial interest in Boehringer Ingelheim, PDL BioPharma, Inc., Terumo Neurovascular Monitoring, NCME, and Bayer Schering Pharma; has received research support from ImaRx Therapeutics, Inc., Guidant, Cordis, Bard Peripheral Vascular, Inc., Abbott, Boston Scientific, and the NIH/NINDS; estimates that $<10 \%$ of his clinical effort is spent on transcranial Doppler; and has given expert testimony in a legal proceeding related to this manuscript. Dr. Sorensen serves on scientific advisory boards for Olea Medical, Siemens Healthcare, Genentech, Inc., Lantheus Medical Imaging, Mitsubishi Tanabe Pharma Corporation, Takeda Pharmaceutical Company Limited/Millennium Pharmaceuticals, Inc., AstraZeneca, the NIH, and Bayer Schering Pharma; has received funding for travel from the NIH,
Siemens Healthcare, and Genentech, Inc.; serves as a Section Editor for Stroke and on the editorial boards of the Journal of Clinical Oncology and The Oncologist; has served as a consultant for Mitsubishi Tanabe Pharma Corporation, AstraZeneca, Genentech, Inc., Novartis, Lantheus Medical Imaging, and Bayer Schering Pharma; holds patents re: Method for evaluating novel, stroke treatments using a tissue risk map, Imaging system for obtaining quantitative perfusion indices, Delay-compensated calculation of tissue blood flow, High-flow oxygen delivery system and methods of use thereof, and Magnetic resonance spatial risk map for tissue outcome prediction; receives royalties from the publication of Cerebral MR Perfusion Imaging: Principles and Current Applications (Thieme, 2000); estimates that $10 \%$ of his clinical effort is spent on MRI; has received research support from Schering-Plough Corp., AstraZeneca, Exelixis, Genentech, Inc. Novartis, Takeda Pharmaceutical Company Limited/Millennium Pharmaceuticals, Inc., Surface Logix Inc., Siemens Healthcare, the NIH (NINDS R01NS38477, NINDS R01NS063925, NINDS R21NS061119, NCI CA137254, and NCRR), and from Aarhus University; receives royalty and license fee payments from Bayer Schering Pharma; holds stock options in EPIX Pharmaceuticals, Inc.; and has given expert testimony in legal proceedings. Dr. Warach serves on the editorial boards of the Journal of Cerebral Blood Flow and Metabolism, Stroke, The Lancet Neurology, and the International Journal of Stroke; and is an employee of NIH, receiving research support exclusively from the Division of Intramural Research of NIH, which includes collaboration agreements with General Electric and Olea Medical.

\section{DISCLAIMER}

This statement is provided as an educational service of the American Academy of Neurølogy. It is based on an assessment of current scientific and clinical information. It is not intended to include all possible proper methods of care for a particular neurologic problem or all legitimate criteria for choosing a specific procedure. Neither is it intended to exclude any reasonable alternative methodologies. The AAN recognizes that specific patient care decisions are the prerogative of the patient and the physician caring for the patient, based on all of the circumstances involved. The clinical context section is made available in order to place the evidencebased guideline(s) into perspective with current practice habits and challenges. No formal practice recommendations should be inferred.

\section{CONFLICT OF INTEREST}

The American Academy of Neurology is committed to producing independent, critical and truthful clinical practice guidelines (CPGs). Significant efforts are made to minimize the potential for conflicts of interest to influence the recommendations of this CPG. To the extent possible, the AAN keeps separate those who have a financial stake in the success or failure of the products appraised in the CPGs and the developers of the guidelines. Conflict of interest forms were obtained from all authors and reviewed by an oversight committee prior to project initiation. AAN limits the participation of authors with substantial conflicts of interest. The AAN forbids commercial participation in, or funding of, guideline projects. Drafts of the guideline have been reviewed by at least three AAN committees, a network of neurologists, Neurology ${ }^{\circledR}$ peer reviewers, and representatives from related fields. The AAN Guideline Author Conflict of Interest Policy can be viewed at www.aan.com.

Received August 6, 2009. Accepted in final form April 25, 2010.

\section{REFERENCES}

1. Lloyd-Jones D, Adams R, Carnethon M, et al. Heart disease and stroke statistics: 2009 update: a report from the American Heart Association statistics committee and stroke statistics subcommittee. Circulation 2009;119:e21e181.

2. Easton D, Saver JL, Albers GW, et al. Definition and evaluation of transient ischemic attack: a scientific statement for healthcare professionals from the American Heart Association/American Stroke Association Stroke Council. Stroke 2009; 40:2276-2293. 
3. Adams HP Jr, del Zoppo G, Alberts MJ, et al. Guidelines for the early management of adults with ischemic stroke: a guideline from the American Heart Association/American Stroke Association Stroke Council. Stroke 2007;38:1655_1711.

4. The National Institute of Neurological Disorders and Stroke rt-PA Stroke Study Group. Tissue plasminogen activator for acute ischemic stroke. N Engl J Med 1995;333: 1581-1587.

5. Hacke W, Kaste M, Bluhmki E, et al. Thrombolysis with alteplase 3 to 4.5 hours after acute ischemic stroke. N Engl J Med 2008;359:1317-1329.

6. del Zoppo GJ, Saver JL, Jauch EC, et al. Expansion of the time window for treatment of acute ischemic stroke with intravenous tissue plasminogen activator: a science advisory from the American Heart Association/American Stroke Association. Stroke 2009;40:2945-2948.

7. Fiebach JB, Schellinger PD, Gass A, et al. Stroke magnetic resonance imaging is accurate in hyperacute intracerebral hemorrhage: a multicenter study on the validity of stroke imaging. Stroke 2004;35:502-507.

8. Kidwell CS, Chalela JA, Saver JL, et al. Comparison of MRI and CT for detection of acute intracerebral hemorrhage. JAMA 2004;292:1823-1830.

9. von Kummer R, Allen KL, Holle R, et al. Acute stroke: usefulness of early CT findings before thrombolytic th apy. Radiology 1997;205:327-333.

10. Barber PA, Demchuk AM, Zhang J, Buchan AM. Validity and reliability of a quantitative computed tomography score in predicting outcome of hyperacute stroke before thrombolytic therapy: ASPECTS Study Group Alberta Stroke Programme Early CT Score. Lancet 2000;355: $1670-1674$.

11. von Kummer R, Bozzao L, Manelfe C, eds. Early CT Diagnosis of Hemispheric Brain Infarction, 1st ed. Berlin: Springer Verlag; 1995

12. Patel SC, Levine SR, Tilley BC, et al. Lack of clinical significance of early ischemic changes on computed tomography in acute stroke. JAMA 2001;286:2830-2838.

13. Fiebach JB, Schellinger PD, Jansen O, et al. CT and diffusion-weighted MR imaging in randomized order: diffusion-weighted imaging results in higher accuracy and lower interrater variability in the diagnosis of hyperacute ischemic stroke. Stroke 2002;33:2206-2210.

14. Schellinger PD, Fiebach JB, Hacke W. Imaging-based decision making in thrombolytic therapy for ischemic stroke: present status. Stroke 2003;34:575-583.

15. Warach S. Stroke neuroimaging. Stroke 2003;34:345347.

16. Liu Y, Laakso MP, Karonen JO, et al. Apolipoprotein E polymorphism and acute ischemic stroke: a diffusion- and perfusion-weighted magnetic resonance imaging study. J Cereb Blood Flow Metab 2002;22:1336-1342.

17. Moseley ME, Cohen Y, Mintorovitch J, et al. Early detection of regional cerebral ischemia in cats: comparison of diffusion- and T2-weighted MRI and spectroscopy. Magn Reson Med 1990;14:330-346.

18. Rosen BR, Belliveau JW, Vevea JM, Brady TJ. Perfusion imaging with NMR contrast agents. Magn Reson Med 1990;14:249-265.

19. Buckley BT, Wainwright A, Meagher T, Briley D. Audit of a policy of magnetic resonance imaging with diffusionweighted imaging as first-line neuroimaging for in-patients with clinically suspected acute stroke. Clin Radiol 2003; 58:234-237.

20. Schellinger PD, Jansen O, Fiebach JB, et al. Feasibility and practicality of MR imaging of stroke in the management of hyperacute cerebral ischemia. AJNR Am J Neuroradiol 2000;21:1184-1189.

21. von Kummer R. Imaging of stroke pathology without predefined gold standard. Cerebrovasc Dis 2002;14:270; author reply 271.

22. Albers GW, Thijs VN, Wechsler L, et al. Magnetic resonance imaging profiles predict clinical response to early reperfusion: the diffusion and perfusion imaging evaluation for understanding stroke evolution (DEFUSE) study. Ann Neurol 2006;60:508-517.

23. Schellinger PD, Thomalla G, Fiehler J, et al. MRI-based and CT-based thrombolytic therapy in acute stroke within and beyond established time windows: an analysis of 1210 patients. Stroke 2007;38:2640-2645.

24. Davis SM, Donnan GA, Parsons MW, et al. Effects of alteplase beyond $3 \mathrm{~h}$ after stroke in the Echoplanar Imaging Thrombolytic Evaluation Trial (EPITHET): a placebo-controlled randomised trial. Lancet Neurol 2008; 7:299-309.

Furlan AJ, Eyding D, Albers GW, et al. Dose Escalation of Desmoteplase for Acute Ischemic Stroke (DEDAS): evidence of safety and efficacy 3 to 9 hours after stroke onset. Stroke 2006;37:1227-1231.

6. Hacke W, Albers G, Al-Rawi Y, et al. The Desmoteplase in Acute Ischemic Stroke Trial (DIAS): a phase II MRI-based 9-hour window acute stroke thrombolysis trial with intravenous desmoteplase. Stroke 2005;36:66-73.

27. Hacke W, Furlan AJ, Al-Rawi Y, et al. Intravenous desmoteplase in patients with acute ischaemic stroke selected by MRI perfusion-diffusion weighted imaging or perfusion CT (DIAS-2): a prospective, randomised, doubleblind, placebo-controlled study. Lancet Neurol 2009;8: 141-150.

28. Chalela JA, Kidwell C, Nentwich L, et al. Magnetic resonance imaging and computed tomography in emergency assessment of patients with suspected acute stroke: a prospective comparison. Lancet 2007;369:293-398.

29. Barber PA, Hill MD, Eliasziw M, et al. Imaging of the brain in acute ischaemic stroke: comparison of computed tomography and magnetic resonance diffusionweighted imaging. J Neurol Neurosurg Psychiatry 2005;76:1528-1533.

30. Grandin CB, Duprez TP, Smith AM, et al. Usefulness of magnetic resonance-derived quantitative measurements of cerebral blood flow and volume in prediction of infarct growth in hyperacute stroke. Stroke 2001;32: 1147-1153.

31. Karonen JO, Ostergaard L, Vainio P, et al. Diffusion and perfusion MR imaging in acute ischemic stroke: a comparison to SPECT. Comput Methods Programs Biomed 2001;66:125-128.

32. Schaefer PW, Hunter GJ, He J, et al. Predicting cerebral ischemic infarct volume with diffusion and perfusion MR imaging. AJNR Am J Neuroradiol 2002;23:1785-1794.

33. Wittsack HJ, Ritzl A, Fink GR, et al. MR imaging in acute stroke: diffusion-weighted and perfusion imaging parameters for predicting infarct size. Radiology 2002;222:397403.

34. Linfante I, Llinas RH, Schlaug G, Chaves C, Warach S, Caplan LR. Diffusion-weighted imaging and National Insti- 
tutes of Health Stroke Scale in the acute phase of posteriorcirculation stroke. Arch Neurol 2001;58:621-628.

35. Fink JN, Selim MH, Kumar S, et al. Is the association of National Institutes of Health Stroke Scale scores and acute magnetic resonance imaging stroke volume equal for patients with right- and left-hemisphere ischemic stroke? Stroke 2002;33:954-958.

36. Lovblad KO, Baird AE, Schlaug G, et al. Ischemic lesion volumes in acute stroke by diffusion-weighted magnetic resonance imaging correlate with clinical outcome. Ann Neurol 1997;42:164-170.

37. Warach S, Pettigrew LC, Dashe JF, et al. Effect of citicoline on ischemic lesions as measured by diffusion-weighted magnetic resonance imaging: Citicoline 010 Investigators. Ann Neurol 2000;48:713-722.

38. Baird AE, Dambrosia J, Janket S, et al. A three-item scale for the early prediction of stroke recovery. Lancet 2001; 357:2095-2099.

39. Thijs VN, Lansberg MG, Beaulieu C, Marks MP, Moseley ME, Albers GW. Is early ischemic lesion volume on diffusion-weighted imaging an independent predictor of stroke outcome? A multivariable analysis. Stroke 2000;31: 2597-2602.

40. Fiebach J, Jansen O, Schellinger P, et al. Comparison of CT with diffusion-weighted MRI in patients with hyperacute stroke. Neuroradiology 2001;43:628-632.

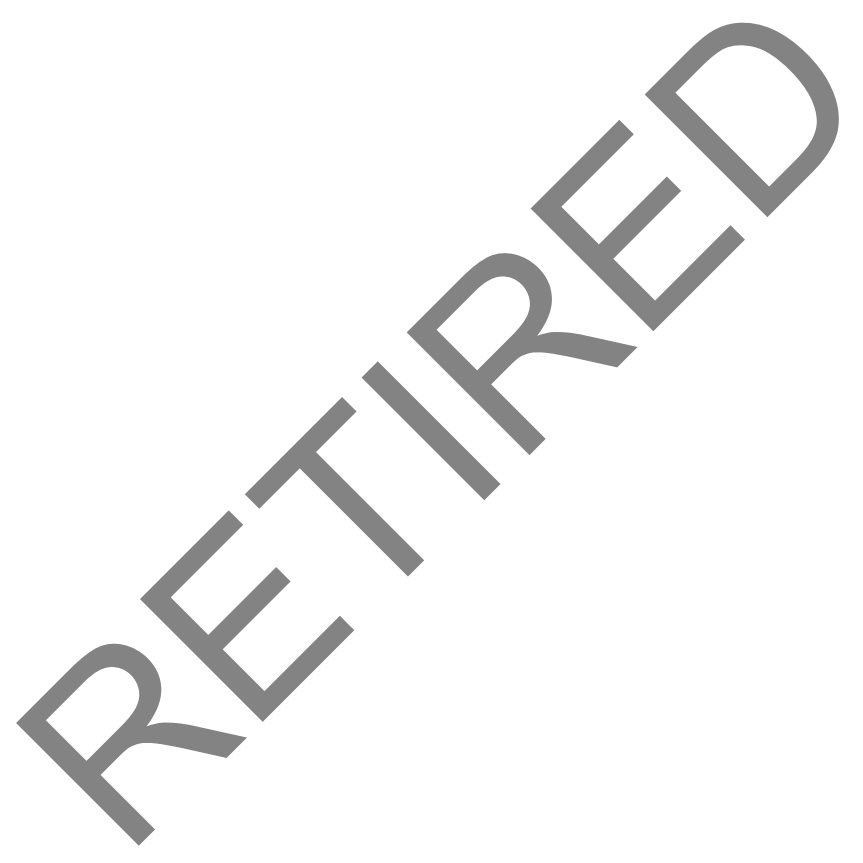




\title{
Neurology
}

\author{
Evidence-based guideline: The role of diffusion and perfusion MRI for the diagnosis of \\ acute ischemic stroke [RETIRED]: Report of the Therapeutics and Technology \\ Assessment Subcommittee of the American Academy of Neurology \\ P.D. Schellinger, R.N. Bryan, L.R. Caplan, et al. \\ Neurology 2010;75;177-185 \\ DOI 10.1212/WNL.0b013e3181e7c9dd
}

This information is current as of July 12, 2010

Updated Information \& Services

Supplementary Material

Citations

Subspecialty Collections

Errata

Permissions \& Licensing

Reprints including high resolution figures, can be found at: http://n.neurology.org/content/75/2/177.full

Supplementary material can be found at: http://n.neurology.org/content/suppl/2010/07/11/75.2.177.DC1 http://n.neurology.org/content/suppl/2010/07/11/75.2.177.DC2 http://n.neurology.org/content/suppl/2010/12/19/75.2.177.DC4 http://n.neurology.org/content/suppl/2010/12/19/75.2.177.DC3

This article has been cited by 32 HighWire-hosted articles: http://n.neurology.org/content/75/2/177.full\#\#otherarticles

This article, along with others on similar topics, appears in the following collection(s):

DWI

http://n.neurology.org/cgi/collection/dwi

An erratum has been published regarding this article. Please see next page or:

/content/75/10/938.2.full.pdf

Information about reproducing this article in parts (figures,tables) or in its entirety can be found online at:

http://www.neurology.org/about/about_the_journal\#permissions

Information about ordering reprints can be found online:

http://n.neurology.org/subscribers/advertise

Neurology ${ }^{\circledR}$ is the official journal of the American Academy of Neurology. Published continuously since 1951, it is now a weekly with 48 issues per year. Copyright . All rights reserved. Print ISSN: 0028-3878. Online ISSN: 1526-632X.

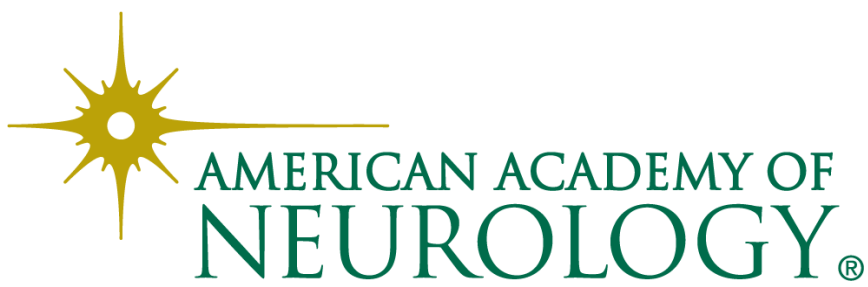


2. Fletcher CF, Tottene A, Lennon VA, et al. Dystonia and cerebellar atrophy in Cacnala null mice lacking P/Q calcium channel activity. FASEB J 2001;15:1288-1290.

3. Raike RS, Jinnah HA, Hess EJ. Animal models of generalized dystonia. NeuroRx 2005;2:504-512.

4. Shirley TL, Rao LM, Hess EJ, Jinnah HA. Paroxysmal dyskinesias in mice. Mov Disord 2008;23:259-264.

5. Miki T, Zwingman TA, Wakamori M, et al. Two novel alleles of tottering with distinct $\mathrm{Ca}(\mathrm{v}) 2.1$ calcium channel neuropathologies. Neuroscience 2008;155:31-44.

6. Xie G, Clapcote SJ, Nieman BJ, et al. Forward genetic screen of mouse reveals dominant missense mutation in the P/Q-type voltage-dependent calcium channel, CACNA1A. Genes Brain Behav 2007;6:717-727.

7. Hess EJ. Migraines in mice? Cell 1996;87:1149-1151.

8. Cuenca-Leon E, Banchs I, Serra SA, et al. Late-onset episodic ataxia type 2 associated with a novel loss-of-function mutation in the CACNA1A gene. J Neurol Sci 2009;280:10-14.

9. Spacey SD, Materek LA, Szczygielski BI, Bird TD. Two novel $C A C N A 1 A$ gene mutations associated with episodic ataxia type 2 and interictal dystonia. Arch Neurol 2005;62: 314-316.

10. Sethi KD, Jankovic J. Dystonia in spinocerebellar ataxia type 6. Mov Disord 2002;17:150-153.

\section{CORRECTION}

Increased diffusivity in acute multiple sclerosis lesions predicts risk of black hole

In the article "Increased diffusivity in acute multiple sclerosis lesions predicts risk of black hole" by R.T. Naismith et al. (Neurology ${ }^{\circledR} 2010 ; 74: 1694-1701$ ), the authors inadvertently omitted a grant acknowledgment: NIH P01 NS059560 to A.H.C. The authors regret the error.

\section{CORRECTION}

Evidence-based guideline: The role of diffusion and perfusion MRI for the diagnosis of acute ischemic stroke: Report of the Therapeutics and Technology Assessment Subcommittee of the American Academy of Neurology In the byline of the article "Evidence-based guideline: The role of diffusion and perfusion MRI for the diagnosis of acute ischemic stroke: Report of the Therapeutics and Technology Assessment Subcommittee of the American Academy of Neurology" by Schellinger et al. (Neurology $\left.{ }^{\circledR} 2010 ; 75: 177-185\right)$, Dr. Schellinger's degree should have been listed as "MD." The authors regret the error. 